\title{
Adrenoleukodystrophy: Impaired Oxidation of Very Long Chain Fatty Acids in White Blood Cells, Cultured Skin Fibroblasts, and Amniocytes
}

\author{
INDERJIT SINGH, ${ }^{(41)}$ ANN E. MOSER, HUGO W. MOSER, AND YASUO KISHIMOTO \\ John F. Kennedy Institute, and the Departments of Neurology and Pediatrics, Johns Hopkins University, \\ Baltimore, Maryland, USA
}

\begin{abstract}
Summary
We compared the formation of ${ }^{14} \mathrm{CO}_{2}$ from $\left[\mathrm{I}-{ }^{14} \mathrm{Clfatty}\right.$ acids in homogenates of cultured skin fibroblasts and white blood cells from 25 patients with adrenoleukodystrophy (ALD) and from 24 controls. The ALD group included 16 boys with childhood ALD, five men with adrenomyeloneuropathy (AMN), and two boys and two girls with neonatal ALD. The substrates were unbranched saturated fatty acids ranging in chain length from 16-26 carbons. From C24:0, the radioactive $\mathrm{CO}_{2}$ production by homogenates of ALD fibroblasts and white blood cells was $17 \%$ and $37 \%$ of control, respectively, and from C26:0 it was $17 \%$ of control in ALD fibroblasts. The $\mathrm{CO}_{2}$ evolution from palmitate (C16:0) in the ALD was identical to the control group; for C18:0, the value for ALD cells was $76 \%$ of control, and fatty acids with chain lengths between $\mathrm{C18:0}$ and $\mathrm{C24:0}$ gave intermediate results. Results for childhood ALD patients were similar to those for the AMN patients. More limited studies with cultured amniocytes of fetuses with childhood ALD gave results similar to those obtained with cultured skin fibroblasts, and results with neonatal ALD patients appeared to be the same as for childhood ALD and AMN. Studies of three women who were carriers for childhood ALD gave values intermediate between ALD and control. The total C26:0 levels in ALD cultured skin fibroblasts and white blood cells were 4-6 times that of control; the total C24:0 levels were increased 10-30\%, whereas the $\mathrm{C} 22: 0$ levels were unchanged.

The results suggest that ALD patients have a defect in the oxidation of very long chain fatty acids (C24:0 and longer) but not for the degradation of fatty acids with a chain length of 18 carbons or less. Such a defect could account for the accumulation of the very long chain fatty acids in a variety of tissues and lipid moieties. The accumulation of these fatty acids, coupled with the metabolic data presented here, suggests that normal catabolism of very long chain fatty acids involves a metabolic pathway which is distinct from that for other fatty acids, and that this pathway is genetically deficient in patients with ALD.
\end{abstract}

\section{Abbreviations}

ALD, adrenoleukodystrophy

AMN, adrenomyeloneuropathy

C22:0, docosanoic acid (behenic acid)

C24:0, tetracosanoic acid (lignoceric acid)

C26:0, hexacosanoic acid (cerotic acid)

C27:0, heptacosanoic acid

GLC, gas liquid chromatography

WBC, white blood cell
ALD is a genetically-determined, progressive disorder which affects mainly the adrenal cortex and the white matter of the nervous system (32). It is associated with the accumulation of saturated very long chain fatty acids (mainly C26:0, C25:0, and $\mathrm{C} 24: 0$ ) in the cholesterol esters and gangliosides in these tissues $(11,17,30)$. Accumulation of these same fatty acids has also been reported in sphingomyelin and other lipid moieties of plasma (23) and red blood cells (38) and in cultured skin fibroblasts (22), cultured muscle cells (1), and cultured amniocytes (24).

Several types of ALD have been described. The most common type is the childhood form (32) that usually presents between age 4 and 8 years, involves mainly the cerebral white matter and adrenal cortex, and leads to death during the first or second decade. Pedigree analysis is consistent with X-linked mode of inheritance (32). This has been confirmed by studies with cultured skin fibroblasts and the ALD gene has been mapped to Xq28 (19). AMN, another type of ALD, occurs mainly in adults, progresses more slowly, and in addition to adrenal cortex involves mainly the white matter of the spinal cord and peripheral nerves (8). ALD and AMN have been described in the same kindred (4) and it is considered likely that ALD and AMN represent different forms of the same disease process. Recent interest has been focused on a new entity referred to as connatal or neonatal adrenoleukodystrophy $(2,3,9,12,16,21,38)$. This early onset disorder shows the same degree of accumulation of very long chain fatty acids as childhood ALD and AMN, but differs from them in that it involves a wider range of tissues. Furthermore, neonatal-connatal ALD involves girls as frequently and as severely as it does boys, and there is circumstantial evidence that it is inherited as an autosomal recessive trait $(9$, 12).

The enzymatic basis for the accumulation of very long chain fatty acids in ALD is unknown. Because the very long chain fatty acid excess in brain and adrenal cortex is present most strikingly in the cholesterol ester fraction, initial enzymatic studies focused on cholesterol esterases. No abnormalities were detected $(18,27)$.

We now report impaired oxidation of very long chain fatty acids in homogenates of white blood cells, and cultured skin fibroblasts and amniocytes from patients with childhood ALD, AMN, and neonatal ALD. Some of the results with cultured skin fibroblasts have been reported previously (33) and the data with white blood cells have been presented as an abstract (34).

\section{MATERIALS AND METHODS}

Patients. We studied 16 boys with childhood ALD (age, 4-16 yr) and five men with AMN (age, 18-50 yr). The neonatal ALD 
cases included two boys, age 2 (12) and 9 yr (3); and two girls, age 2 (12) and 8 yr (21). All of the patients showed the characteristic clinical features as well as elevated levels of very long chain fatty acids in plasma (23) and cultured skin fibroblasts (22). The ALD cultured amniocytes were derived from male fetuses at risk for childhood ALD, in whom the diagnosis was confirmed by postmortem studies of fetal tissues after induced abortion (24). Control cells were derived from 20 normal men and women age 12-30 yr, and from four patients with sphingolipidoses (Farber's disease, metachromatic leukodystrophy, globoid leukodystrophy, and Fabry's disease).

Materials. $\left[1-{ }^{14} \mathrm{C}\right]$ Palmitic and $\left[1-{ }^{14} \mathrm{C}\right]$ stearic acids and $\mathrm{K}^{14} \mathrm{CN}$ were purchased from New England Nuclear, Boston, MA. Other $\left[1-{ }^{14} \mathrm{C}\right]$ labeled fatty acids were synthesized according to the procedure described previously $(10,26)$. ATP, CoASH, and NAD were obtained from PL-Biochemicals, Milwaukee, WI and malate, FAD, and alpha-cyclodextrin from Sigma Chemical Co., St. Louis, MO. L-Carnitine was a gift of Dr. Yuzo Kawashima, Otsuka Pharmaceutical Co., Tokushima, Japan.

Isolation of white blood cells. Ten milliliters of heparinized blood was mixed with $5 \mathrm{ml}$ of $6 \%$ dextran, $3.5 \mathrm{ml}$ of $5 \%$ glucose, and $1.5 \mathrm{ml}$ of ACD solution $(2.45 \%$ glucose, $2.2 \%$ sodium citrate dihydrate, and $0.73 \%$ citric acid) and allowed to stand for $30-40$ min at room temperature or until the red blood cells had settled out. The upper layer was removed by suction and centrifuged at $350 \times g$ for $15 \mathrm{~min}$. The supernatant fraction was discarded and the residual red cells in the pellet were lysed by the addition of hypotonic sodium chloride solution for $2 \mathrm{~min}$ before being returned to isotonic saline. The leukocytes were then collected by centrifugation.

Cultured skin fibroblasts and amniocytes. Fibroblasts were grown in a $5 \%$ carbon dioxide atmosphere at $37^{\circ} \mathrm{C}$ in Eagle's minimum essential medium plus Earle's salts and $13 \%$ fetal calf serum. The cells were harvested 3-4 d after confluence, treated with $0.2 \%$ trypsin, and centrifuged. The amniocytes were prepared in the same way except that $15 \%$ fetal calf serum was used.

Preparation of homogenates. Cells were homogenized by 20 passes with a hand-driven Teflon coated glass homogenizer in $0.06 \%$ sodium chloride.

Enzyme assay. The reaction mixture contained 12 micromolar $\left[1-{ }^{14} \mathrm{C}\right]$ fatty acid (approximately $6 \times 10^{5} \mathrm{dpm}$ ) coated on Celite, $20 \mathrm{mM}$ MOPS-HCl buffer, $\mathrm{pH} 7.0,30 \mathrm{mM} \mathrm{KCl}, 1 \mathrm{mM} \mathrm{MgCl}$, 8.5 mM ATP, $0.25 \mathrm{mM}$ NAD, $0.17 \mathrm{mM}$ FAD, $0.5 \mathrm{mM}$ malate, $2.5 \mathrm{mM}$ L-carnitine, $0.08 \mathrm{mM} \mathrm{CoASH}$, and $1 \mathrm{mg}$ of alphacyclodextrin in a total volume of $0.6 \mathrm{ml}$. The reaction was started by addition of the cell homogenates containing $200-500 \mu \mathrm{g}$ of protein. The mixture was incubated at $37^{\circ} \mathrm{C}$ for $1 \mathrm{~h}$ in a side arm test tube. The reaction was stopped by the addition of $0.25 \mathrm{ml}$ of $3 \mathrm{~N} \mathrm{H}_{2} \mathrm{SO}_{4}$ from the side arm tube and the radioactivity was collected in a glass fiber filter hanging from the top and measured as described previously (25). We showed previously that $\mathrm{CO}_{2}$ evolution in homogenates of ALD and control fibroblasts was linear with time up to $80 \mathrm{~min}$, and with protein concentration up to $400 \mu \mathrm{g}(33)$.

Proteins were measured by the procedure of Miller (20) with bovine serum albumin as the standard. Fatty acids were quantitated by capillary gas liquid chromatography (23).

\section{RESULTS}

Figure 1 shows that production of ${ }^{14} \mathrm{CO}_{2}$ from $\left[1-{ }^{14} \mathrm{C}\right]$ labeled very long chain fatty acids is significantly reduced in homogenates of ALD cultured skin fibroblasts or white blood cells. The differences are most striking for $\mathrm{C} 24: 0$, where the $\mathrm{CO}_{2}$ production was $16 \%$ and $37 \%$ of control for fibroblasts and white blood cells, respectively, and the differences are statistically significant with $P$ values of less than 0.001 . For C26:0 the value was $17 \%$ of control in fibroblasts but, probably due to the smaller number of samples tested statistical significance was only at the 0.05
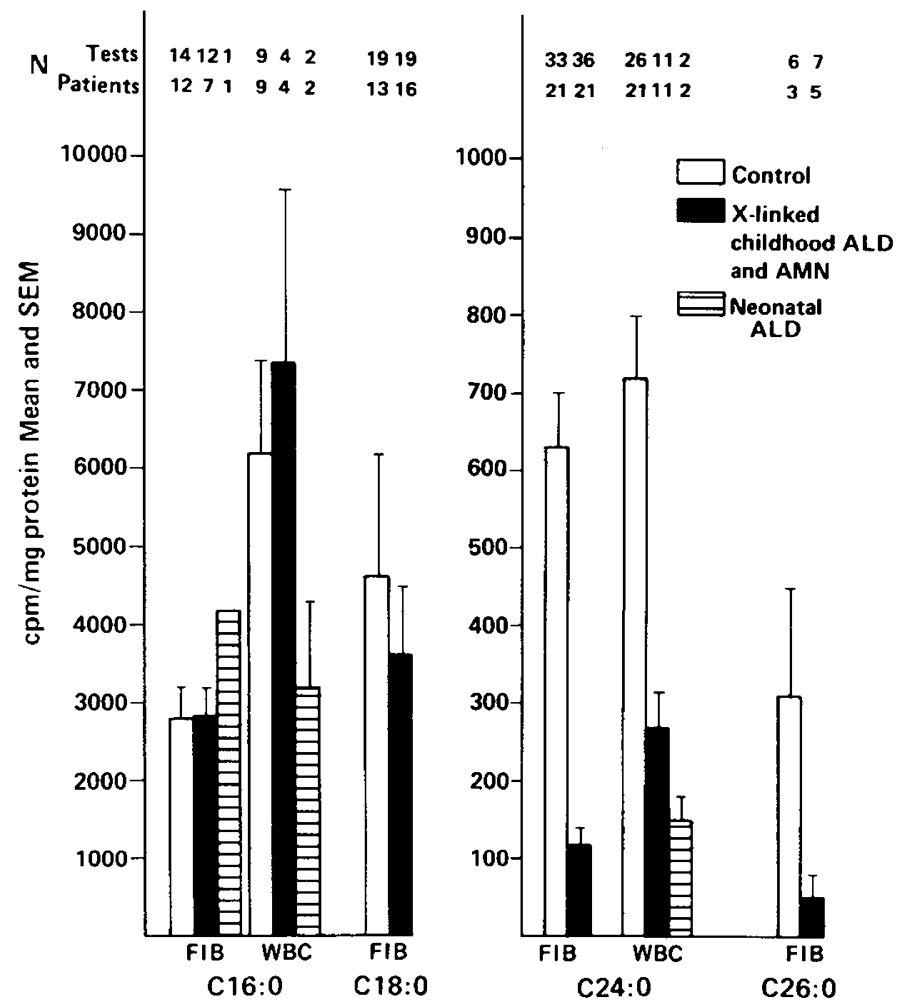

Fig. 1. Production of $\left[{ }^{14} \mathrm{C}\right] \mathrm{CO}_{2}$ from $\left[\mathrm{I}^{14}{ }^{14} \mathrm{C}\right]$ fatty acids in homogenates of cultured skin fibroblasts and white blood cells. Bar graphs show mean and SEM. Note difference in scale for C16:0, C18:0, vs. C24:0 and C26:0. Almost all of the tests were done in duplicate. In several instances repeat sets of analyses were done on samples from the same patient. The results for childhood adrenoleukodystrophy (ALD) and adrenomyeloneuropathy (AMN) patients are grouped together. There was no apparent difference between them. The differences between ALD and controls for C24:0 oxidation in both fibroblasts and plasma are statistically significant $(P<$ 0.001 ). Abbreviations: FIB, fibroblasts and WBC, white blood cells.

level. In contrast, $\mathrm{CO}_{2}$ production from $\left[1-{ }^{14} \mathrm{C}\right] \mathrm{C} 16: 0$ in $\mathrm{ALD}$ fibroblasts was identical to control, and only insignificantly increased over control in the white blood cells. $\mathrm{CO}_{2}$ production from $\mathrm{C} 18: 0$ in ALD fibroblasts was $76 \%$ of control, and this difference was not statistically significant. The results were similar regardless of whether they were obtained from childhood ALD or AMN patients (data not shown), and limited studies with four patients with neonatal ALD suggest that results are similar to those in childhood ALD and AMN.

Figure 2 shows the ratios between ${ }^{14} \mathrm{CO}_{2}$ production from [1$\left.{ }^{14} \mathrm{C}\right] \mathrm{C} 16: 0$ and $\left[1-{ }^{14} \mathrm{C}\right] \mathrm{C} 24: 0$. Use of this ratio may reduce variations attributable to differences in homogenization or other experimental conditions. For ALD cultured skin fibroblasts and white blood cells, respectively, this ratio is 4.1 and 3.2 times control. Both differences are statistically significant. For white blood cells the $P$ value was less than 0.001 whereas for fibroblasts it was less than 0.01 . Limited data with ALD cultured amniocytes suggest that results with these cells are equivalent to those with cultured skin fibroblasts. Studies with white blood cells from three women who are obligate heterozygotes for X-linked ALD gave $\mathrm{C} 16: 0 / \mathrm{C} 24: 0$ ratios intermediate $(29.6 \pm 5)$ between control $(18.5 \pm 2.7)$ and the ALD hemizygote $(41.9 \pm 10)$.

Figure 3 shows the variation of ${ }^{14} \mathrm{CO}_{2}$ production from $\left[1-{ }^{14} \mathrm{C}\right]$ fatty acids in homogenates of ALD and control cultured skin fibroblasts as a function of fatty acid chain length. Although there are no differences between ALD and control for $\mathrm{C} 16: 0$ and $\mathrm{C} 18: 0$, the rate of $\mathrm{CO}_{2}$ evolution for the fatty acids with longer chain length decreased more rapidly for ALD samples than for controls. 


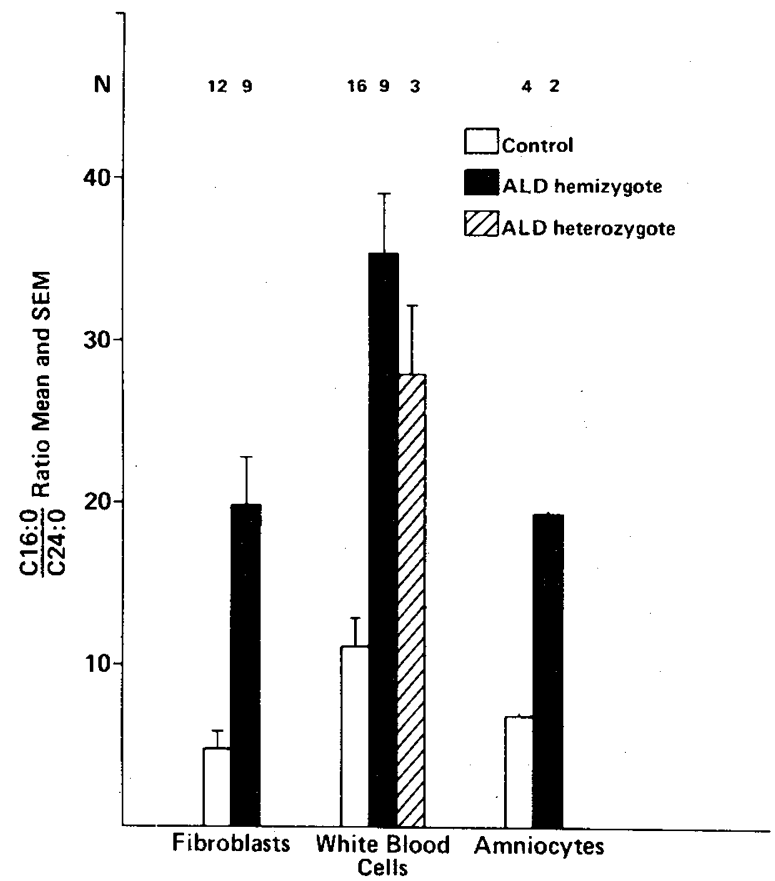

Fig. 2. Ratios between $\left[{ }^{14} \mathrm{C}\right] \mathrm{CO}_{2}$ formed from $\left[1-{ }^{14} \mathrm{C}\right] \mathrm{C} 16: 0$ and $\mathrm{C} 24: 0$ fatty acids in homogenates of cultured skin fibroblasts, white blood cells, and amniocytes. The ratios between $\left[{ }^{14} \mathrm{CO}_{2}\right]$ formed from $\mathrm{C} 16: 0$ to that formed from $\mathrm{C} 24: 0$ are significantly higher for patients with childhood adrenoleukodystrophy (ALD) or AMN adrenomyeloneuropathy (ALD hemizygotes) than for controls. For white blood cells there was a statistically significant difference between these ratios $(P<0.001)$, and for fibroblasts, $P<0.01$. Results with cultured amniocytes resemble those for cultured skin fibroblasts, whereas in white blood cells the values for women who are carriers for ALD are intermediate between control and ALD hemizygotes; however, the number of samples was too small for statistical analysis.

Because the observed differences of fatty acid oxidation may be related to dilution of exogenous substrates by excess of very long chain fatty acids in ALD cells, we measured the levels of these fatty acids in cultured skin fibroblasts and white blood cells (Table 1). As reported previously $(22,23)$, the level of C22:0 was unaltered whereas the level of C26:0 in fibroblasts and white blood cells respectively was increased to 5.5 and 4.1 times control. In contrast, the C24:0 level was increased only $11-30 \%$ over control. This finding makes it unlikely that the reduced $\mathrm{CO}_{2}$ production from $\mathrm{C} 24: 0$ is due to dilution of the radioactive exogenous substrate by $\mathrm{C} 24: 0$ contained within the tissue sample. In addition, the quantity of exogenous C24:0 (6 nmole per tube) was relatively large in comparison to the total amount of endogenous C24:0 (0.6-1 nmole per tube).

\section{DISCUSSION}

${ }^{14} \mathrm{CO}_{2}$ production from $\left[1-{ }^{14} \mathrm{C}\right] \mathrm{C} 24: 0$ and $\left[1-{ }^{14} \mathrm{C}\right] \mathrm{C} 26: 0$ is reduced significantly in ALD cultured skin fibroblasts, white blood cells, and amniocytes whereas $\mathrm{CO}_{2}$ production from $\mathrm{C16:0}$ is normal. This finding suggests that there is a specific impairment in the oxidation of very long chain fatty acids in ALD, which may account for the tissue accumulation of these substances that is a characteristic of this disorder. Previously reported experiments in which ALD and control fibroblast homogenates were mixed, had ruled out the presence of inhibitors or activators (33). The defect appears to be present in childhood ALD, AMN, and neonatal ALD. This does not necessarily imply, however, that these disorders have the same metabolic basis because $\mathrm{CO}_{2}$ formation from fatty acids requires a large number of separate metabolic steps, and our present studies provide no information about which of these steps is involved.

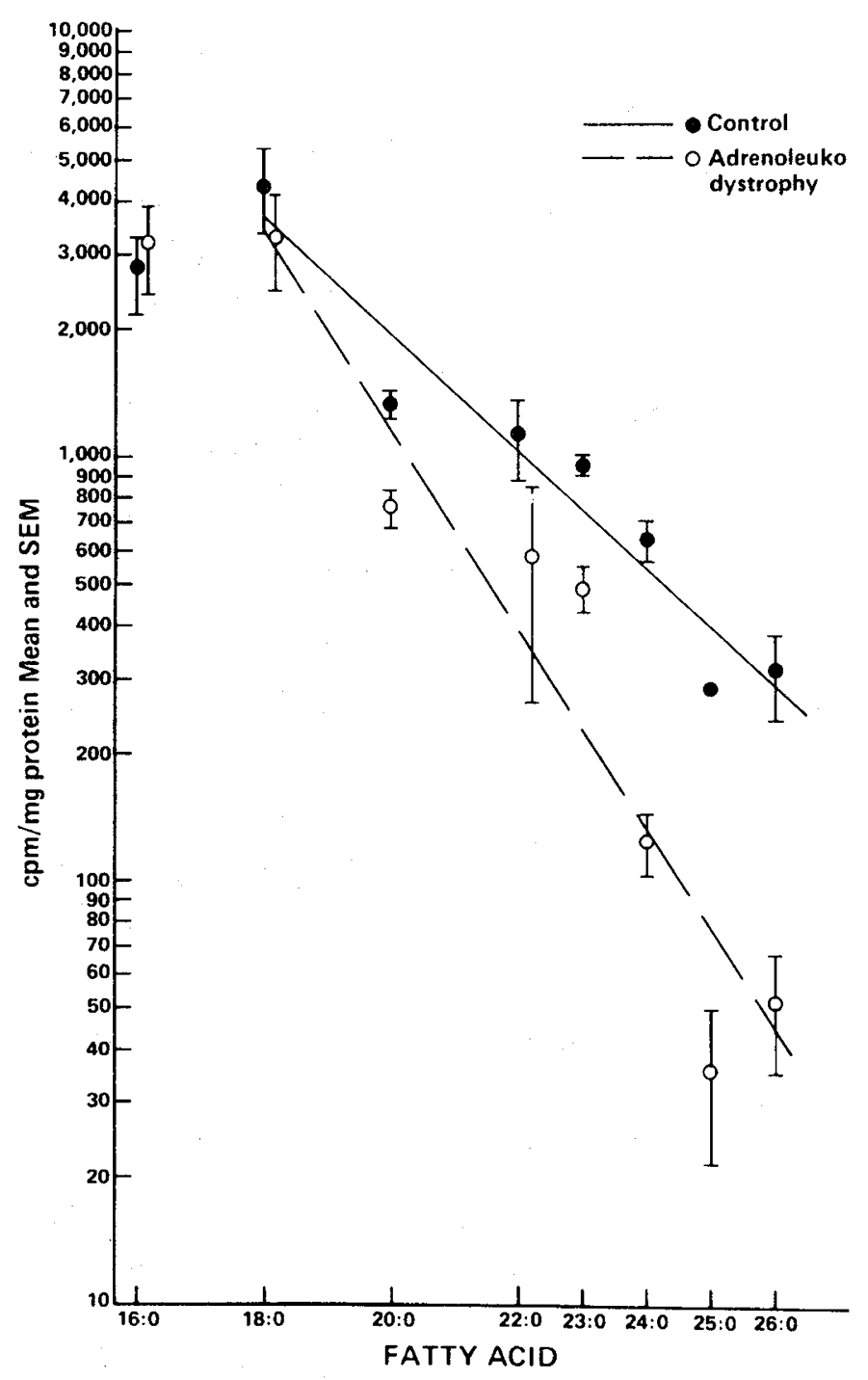

Fig. 3. Formation of $\left[{ }^{14} \mathrm{C}\right] \mathrm{CO}_{2}$ from $\left[\mathrm{II}^{14} \mathrm{C}\right]$ fatty acids by homogenates of cultured skin fibroblasts: variation with chain length. For C16:0, C18:0, and C24:0 each point represents the means and SEM of 14-38 determinations. The points for $\mathrm{C} 26: 0$ represent the mean of six determinations. For the other fatty acids each point represents the mean of duplicate determinations. The lines drawn represent the best fit as determined by least square regression analysis but omitting the value for $\mathrm{Cl} 16: 0 . \mathrm{CO}_{2}$ evolution falls off more rapidly for adrenoleukodystrophy samples than for controls. Note that a semi-log scale is used.

Table 1. Total very long chain fatty acid levels in white blood cells (WBC) and cultured skin fibroblasts expressed as ( $\mu \mathrm{g} / \mathrm{mg}$ protein)*

\begin{tabular}{lccc}
\hline & C22:0 & C24:0 & C26:0 \\
\hline WBC & & & \\
$\quad$ Control & $1.02 \pm 0.36(17)$ & $1.04 \pm 0.41(17)$ & $0.041 \pm 0.019(17)$ \\
ALD & $1.02 \pm 0.40(10)$ & $1.31 \pm 0.34(10)$ & $0.17 \pm 0.085(10)$ \\
Fibroblasts & & & \\
$\quad$ Control & $0.99 \pm 0.44(28)$ & $1.73 \pm 0.70(50)$ & $0.074 \pm 0.04(30)$ \\
ALD & $0.88 \pm 0.16(23)$ & $1.93 \pm 0.70(18)$ & $0.41 \pm 0.16(50)$ \\
\hline
\end{tabular}

* Total very long chain fatty acid levels (mean $\pm \mathrm{SD}$ ) in adrenoleukodystrophy (ALD) and control cultured skin fibroblasts and white blood cells. The number of tests performed is shown in parentheses. Total lipids were hydrolyzed with methanolic $\mathrm{HCl}$ and fatty acid methyl esters quantitated by capillary gas liquid chromatography (23). The ALD group included 14 patients with childhood ALD and three patients with adrenomyeloneuropathy. The C26:0 levels are increased 4-6-fold in ALD white blood cells and fibroblasts. The $\mathrm{C} 24: 0$ levels show $10-30 \%$ increases whereas the $\mathrm{C} 22: 0$ levels are unaltered. 
Our results are generally consistent with experiments reported recently by Rizzo et al. (31) in which intact cultured skin fibroblasts or white blood cells were incubated in the presence of $\left[1-{ }^{14} \mathrm{C}\right]$ fatty acids and $\mathrm{CO}_{2}$ evolution was measured. They found that in the ALD fibroblasts $\mathrm{CO}_{2}$ evolution from $\mathrm{C} 24: 0$ and $\mathrm{C} 26: 0$ were 27 and $42 \%$ of control, respectively, compared with $73 \%$

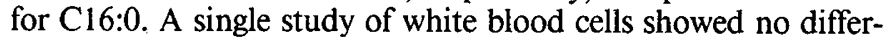
ence between ALD and control.

The results presented here are in apparent conflict with the findings of Tsuji et al. (36) who reported increased accumulation of C26:0 in ALD and AMN cultured skin fibroblasts incubated for $7 \mathrm{~d}$ with $\left[{ }^{14} \mathrm{C}\right] \mathrm{C} 18: 0$, and postulated that the primary defect in ALD involves elevated activity of the fatty acid elongation system. In our view, the results of Tsuji et al. make the significant new observation that ALD and AMN cultured skin fibroblasts do synthesize $C 26: 0$, but in the absence of more complete kinetic data, do not permit conclusion about comparative rates of synthesis or degradation. Their results could also be accounted for by impaired catabolism of newly synthesized $\mathrm{C} 24: 0$ and C26:0. Such a mechanism was found to account for the above normal accumulation of radioactive mucopolysaccharides when cultured skin fibroblasts of Hunter or Hurler disease patients are incubated with radioactive inorganic sulfate (5).

Formation of ${ }^{14} \mathrm{CO}_{2}$ from $\left[1-{ }^{14} \mathrm{C}\right]$ fatty acids involves many steps. The $\mathrm{CO}_{2}$ could be produced either by an alpha- (15) or beta-oxidation mechanism. Alpha-oxidation is utilized for the synthesis of odd chain and alpha-hydroxy fatty acids. Because these substances are present in normal concentrations in ALD tissues, we consider it unlikely that the ALD oxidative defect involves alpha-oxidation.

There are at least three systems for the beta-oxidation of fatty acids. First is the well known mitochondrial system (7); second, the more recently described peroxisomal system $(14,28)$; and third, a system for C24:0 which appears to be specific for brain tissue (37). We consider it unlikely that this last system is involved in ALD because the tissue accumulation of very long chain fatty acids is widespread and in this report we demonstrated that the ALD oxidative defect is present in tissues other than brain.

It is our current hypothesis that the ALD metabolic defect may involve a peroxisomal beta-oxidation system. We favor this hypothesis because 1) long chain fatty acids are known to be oxidized in peroxisomes (14); 2) we presented evidence that the oxidation of $\mathrm{C} 24: 0$ in rat liver takes place in peroxisomes (13); 3) we recently showed that patients with the Zellweger cerebrohepatorenal syndrome have elevated levels of very long chain fatty acid levels (3) and impaired ${ }^{14} \mathrm{CO}_{2}$ production from $\left[1-{ }^{14} \mathrm{C}\right]$ $\mathrm{C} 24: 0$ (Singh, I. unpublished observation) similar to observations in ALD; and 4) patients with the Zellweger syndrome lack peroxisomes $(6,29,39)$. Definition of the metabolic defect in ALD will require study of specified subcellular fractions, and analysis of the separate steps involved in fatty acid degradation. It is a point of challenge and interest that the abnormalities in ALD demonstrated so far suggest that normally there exists a hitherto unrecognized separate system for the degradation of saturated very long chain fatty acids. We believe that it is a component of this system which is genetically deficient in ALD.

\section{REFERENCES AND NOTES}

1. Askanas, V., McLaughlin, J., King, E. W., and Adornato, B. T.: Abnormalities in cultured muscle and peripheral nerve of a patient with adrenoleukodystrophy. N. Engl. J. Med., 301: 588 (1979).

2. Benke, P. J., Reyes, P. F., and Parker, J. C., Jr.: New form of adrenoleukodystrophy. Hum. Genet., 58: 204 (1981)

3. Brown, F. J., McAdams, A. J., Cummins, J. W., Singh, I, Moser, A. B and Moser, H. W.: Cerebro-hepato-renal (Zellweger) syndrome and neonatal adrenoleukodystrophy: similarities in phenotype and accumulation of very long chain fatty acids. Johns Hopkins Med. J., I51: 344 (1982).

4. Davis, L. E., Snyder, R. D., Orth, D. N., Nicholson, W. E., Kornfeld, M., and Seelinger, D. F.: Adrenoleukodystrophy and adrenomyeloneuropathy associated with partial adrenal insufficiency in three generations of a kindred. Am. J. Med. 66: 342 (1979).

5. Fratantoni, J. C., Hall, C. W., and Neufeld, E. F.: The defect in Hurler's and
Hunter's syndromes: faulty degradation of mucopolysaccharide. Proc. Natl. Acad. Sci. USA. 60: 699 (1968).

6. Goldfischer, S, Moore, C. L. Johnson, A. B., Spiro, A. J., Valsamis, M. P Wisniewsky, H. M., Ritch, H. H., Norton, W. T., Rapin, I., and Gartner, L. M.: Peroxisomal and mitochondrial defects in the cerebrohepatorenal syndrome. Science, 182: 62 (1973).

7. Green, D. E. and Allman, D. W.: Fatty acid oxidation. In: D. M. Greenberg: Metabolic Pathways. (Academic Press, New York, 1968)

8. Griffin, J. W., Goren, E., Schaumburg, H., Engel, W. K., and Loriaux, L. Adrenomyeloneuropathy: a probable variant of adrenoleukodystrophy. Neurology 27: 1107 (1977)

9. Haas, J. E., Johnson, E. S., and Farrell, D. L.: Neonatal onset adrenoleukodystrophy in a girl. Ann. Neurol., 12: 449 (1982).

10. Hoshi, M. and Kishimoto, Y.: Synthesis of Cerebronic acid from lignoceric acid by brain preparation: some properties of the alpha hydroxylation system and its distribution. J. Biol. Chem., 248: 4123 (1973).

11. Igarashi, M., Schaumburg, H. H., Powers, J., Kishimoto, Y., Kolodny, E., and Suzuki, K.: Fatty acid abnormality in adrenoleukodystrophy. J. Neurochem. 26: 851 (1976)

12. Jaffe, R., Crumrine, P., Hashida, Y., and Moser, H. W.: Neonatal Adrenoleukodystrophy. Clinical, pathological and biochemical delineation of a syndrome affecting both males and females. Am. J. Path., 108: 100 (1982)

13. Kawamura, N., Moser, H. W., and Kishimoto, Y.: Very long fatty acid oxidation in the rat liver. Biochem. Biophys. Res. Comm., 99: 1216 (1981)

14. Lazarow, P. B.: Different chain length specificities of peroxisomal and mitochondrial enoyl-CoA hydratases. Arch. Biochem. Biophys., 206: 342 (1981).

15. Lippel, K. and Mead, J. F.: Alpha oxidation of 2 hydroxy-tetracosanoate in the rat. Lipids, 4: 129 (1969)

16. Manz, H. J., Schuelein, M., McCullough, D. C., Kishimoto, Y., and Eiben, R. M.: New phenotypic variant of adrenoleukodystrophy. Pathologic, ultrastructural, and biochemical study in two brothers. J. Neurol. Sci., 45: 245 (1980).

17. Menkes, J. H. and Corbo, L. M.: Adrenoleukodystrophy: accumulation of cholesterol esters with very long chain fatty acids. Neurology, 27: 928 (1977).

18. Michels, V. V. and Beaudet, A.: Cholesteryl Lignocerate. Hydrolysis in adrenoleukodystrophy. Pediatr. Res., 14: 21 (1980).

19. Migeon, B. A., Moser, H. W., Moser, A. B., Axelman, J., Sillence, D., and Norum, R. A.: Adrenoleukodystrophy: evidence for X linkage, inactivation, and selection favoring the mutant allele in heterozygous cells. Proc. Natl. Acad. Sci. USA, 78: 5066 (1981).

20. Miller, G. L.: Protein determination for large number of samples. Anal. Chem., 31: 964 (1959).

21. Mobley, W. C., White, C. L., Tennekoon, G., Clark, A. W., Cohen, S. R., Green, W. R., and Moser, H. W.: Neonatal adrenoleukodystrophy. Ann Neurol., 12: 204 (1982)

22. Moser, H. W., Moser, A. B., Kawamura, N., Murphy, J., Suzuki, K, Schaum burg, H., Kishimoto, Y., and Milunsky, A.: Adrenoleukodystrophy: elevated C26:0 fatty acid in cultured skin fibroblasts. Ann. Neurol., 7: 542 (1980).

23. Moser, H. W., Moser, A. B., Frayer, K. K., Chen, W., Schulman, J. D., O'Neill, B. P., and Kishimoto, Y.: Adrenoleukodystrophy: increased plasma content of saturated very long chain fatty acids. Neurology, 31: 1241 (1981)

24. Moser, H. W., Moser, A. B., Powers, J. M., Nitowsky, H. M., Schaumburg, H. H., Norum, R. A., and Migeon, B. R.: The prenatal diagnosis of adrenoleukodystrophy. Demonstration of increased hexacosanoic acid levels in cultured amniocytes and fetal adrenal gland. Pediatr. Res., 16: 172 (1982).

25. Murad, S. and Kishimoto, Y.: Alpha hydroxylation of lignoceric acid to cerebronic acid during brain development. Diminished hydroxylase activity in myelin-deficient mouse mutants. J. Biol. Chem., 250: 5841 (1975)

26. Murad, S., Chen, R. H. K., and Kishimoto, Y.: Alpha-hydroxylation of fatty acids in brain. Substrate specificity and deuterium isotope effect. J. Biol. Chem., 252: 5206 (1977)

27. Ogino, $T$. and Suzuki, K.: Specificities of human and rat brain enzymes of cholesterol ester metabolism toward very long chain fatty acids: implications for biochemical pathogenesis of adrenoleukodystrophy. J. Neurochem., 36 : 776 (1981)

28. Osmundsen, H., Neat, C. E., and Norum, K. R.: Peroxisomal oxidation of long chain fatty acids. FEBS Lett., 99: 292 (1979).

29. Pfeifer, U. and Sandhage, K.: Light and electron microscope liver changes in the cerebro-hepato-renal syndrome of Zellweger (Peroxisomal Deficiency). Virchows Arch. A. Pathol. Anat. and Histol., 384: 269 (1979).

30. Ramsey, R. B., Banik, N. L., and Davison, A. N.: Adrenoleukodystrophy: brain cholesterol esters and other neutral lipids. J. Neurol. Sci., 32: 69 (1977)

31. Rizzo, W., Avigan, J., Knazek, R., and Schulman, J. D.: In vitro investigations of adrenoleukodystrophy (ALD) and adrenomyeloneuropathy (AMN). Clin. Res., 30: 500A (1982)

32. Schaumburg, H. H., Powers, J. H., Raine, C. S., Suzuki, K, and Richardson, E. P., Jr.: Adrenoleukodystrophy. A clinical and pathological study of 17 cases. Arch. Neurol., 32; 577 (1975).

33. Singh, I., Moser, H. W., Moser, A. B., and Kishimoto, Y.: Adrenoleukodystrophy: impaired oxidation of long chain fatty acids in cultured skin fibroblasts and adrenal cortex. Biochem. Biophys. Res. Commun, 102. 1223 (1981).

34. Singh, I., Moser, H. W., Moser, A. B., and Kishimoto, Y.: Impaired oxidation of very long chain fatty acids in adrenoleukodystrophy white blood cells. Pediatr. Res. (abstract), 16: 341A (1982).

35. Tsuji, S., Suzuki, M., Ariga, T., Sekine, M., Kuriyama, M., and Miyatake, T. Abnormality of long-chain fatty acids in erythrocyte membrane sphingomyelin from patients with adrenoleukodystrophy. J. Neurochem., 36: 1046 (1981).

36. Tsuji, S., Sano, T., Ariga, T., and Miyatake, T.: Increased synthesis of hexa- 
cosanoic acid ( $\mathrm{C} 26: 0)$ by cultured skin fibroblasts from patients with adrenoleukodystrophy (ALD) and adrenomyeloneuropathy (AMN). J. Biochem., 90: $1233(1981)$.

37. Uda, M., Singh, I., and Kishimoto, Y.: Glutamate formation from lignoceric acid by rat brain preparation in the presence of pyridine nucleotide and cytosolic factors. Biochemistry, 20: 1295 (1981).

38. Ulrich, J., Herschkowitz, N., Heitz, P., Sigrist, T., and Baerlocher, P.: Adrenoleukodystrophy: preliminary report of a connatal case. Acta Neuropathol. 43: 77 (1978)

39. Versmold, H. T., Bremer, H. J., Herzog, V., Siegel, G., Bassewitz, D. B. V. Irle, U., Voss, H. V., Lombeck, I., and Brauser, B.: A metabolic disorde similar to Zellweger syndrome with hepatic acatalasia and absence of peroxisomes, altered content and redox state of cytochromes and infantile cirrhosis with hemosiderosis. Eur. J. Pediatr., 124: 261 (1977).

40. The authors thank Ms. Angela Liu and Surinder K. Khangoora for their technical assistance.

41. Requests for reprints should be addressed to: Dr. Inderjit Singh, John F. Kennedy Institute, 707 N. Broadway, Baltimore, MD 21205.

42. Supported in part by grants BNS- 8240546 from the National Science Foundation and HD 10981 from the United States Public Health Service.

43. Received for publication December 14, 1982.

44. Accepted for publication May 11, 1983.

\title{
A Comparison between Electrical Impedance and Strain Gauge Plethysmography for the Study of Cerebral Blood Flow in the Newborn
}

\author{
KATE COSTELOE, ${ }^{(24)}$ DIANE P. L. SMYTH, N. MURDOCH, ${ }^{(24)}$ P. ROLFE, ${ }^{(25)}$ AND J. P. M. TIZARD
}

University Department of Paediatrics, John Radcliffe Hospital, Headington, Oxford, England

\section{Summary}

This study investigates the possibility of using pulsatile transcephalic impedance changes, $\Delta Z$, for the continuous monitoring of cerebral blood flow, $\mathrm{CBF}$, in the sick newborn infant. The performance of the impedance method is compared with the measurement of cranial flow, Fc, using a strain gauge for detecting the predicted changes in cerebral blood flow when the baby breathes $2 \% \mathrm{CO}_{2}$ in air, or $\mathrm{O}_{2}$.

In all five studies in which measurements were compared in air and $\mathrm{CO}_{2}$ the expected increases in $\mathrm{Fc}$ and $\Delta \mathrm{Z}$ were seen. In six of seven studies comparing measurements in air and $\mathrm{O}_{2}$ the expected fall in the variables was seen, indicating reduced cerebral blood flow. The problems of both these methods are discussed and we conclude that the impedance method is as good as the strain gauge method for detecting changes in cerebral blood flow.

\section{Abbreviations}

CAT, computerized axial tomography

CBF, cerebral blood flow

CBFa, apparent cerebral blood flow

$\mathrm{CV}$, coefficient of variation

Fc, cranial flow

IVH, intraventricular hemorrhage

OFC, occipitofrontal circumference

$\mathrm{PsO}_{2}$, skin surface oxygen partial pressure

$\Delta \mathrm{Z}$, height of pulsatile impedance signal

Zo ohm, transcephalic impedence

IVH remains a major cause of death and of handicap amongst the survivors of neonatal intensive care $(17,18)$. The introduction of CAT and ultrasound scanning of the brain has facilitated improved diagnosis and grading of IVH $(17,19)$, and studies have identified clinical and physiologic factors that may be associated with its pathogenesis $(7,10)$. More detailed analyses of the physiologic conditions, particularly with reference to intracerebral haemodynamics preceding IVH, have been few. Most of the measurements of CBF that have been made in preterm infants have resulted from studies using radioactively labeled xenon, $(11,12)$. It is not possible to make repeated measurements in an individual baby using this method and in the United Kingdom the technique is generally regarded as unethical. There is a need to establish a safe, non-invasive method for the continuous monitoring of $\mathrm{CBF}$.

The use of several non-invasive methods for obtaining information related to CBF in newborn infants has been described in the literature. These include 1) monitoring intracranial pressure by placing a transducer over the anterior fontanelle $(22), 2$ ) using ultrasound to measure blood flow velocity in the anterior cerebral artery $(1,2)$, and 3$)$ jugular venous occlusion plethysmography using a strain gauge around the $\operatorname{OFC}(3,4)$.

Intracranial pressure can be measured continuously, but we believe it to be of limited value as changes in CBF are not directly reflected by changes in intracranial pressure. Doppler ultrasound gives only a highly indirect indication of flow by measuring the pulsatility index which, by comparing systolic and diastolic blood flow velocities, gives an estimate of the vascular resistance.

Strain gauge measurements can only be intermittent and the quantitative accuracy is limited. The strain gauge method has been shown to detect an increase of $\mathrm{CBF}$ in response to inhaled $2 \% \mathrm{CO}_{2}$ in air, and a decrease of $\mathrm{CBF}$ in response to inhaled $100 \%$ oxygen in the newborn baby $(9,21)$.

We have previously investigated the suitability of electrical impedance plethysmography for the measurement of cardiac output (5) and limb blood flow (6) in the newborn and found that a reliable continuous estimate of flow can be made. Many workers have collected pulsatile electrical impedance data from the adult human head (8). Namon et al. (15) found that the height of the pulsatile impedance signal varies linearly with respect to $\mathrm{CBF}$. The method has been used to monitor changes in the CBF of individuals passing between different sleep states (13), and during the inhalation of increasing $\mathrm{CO}_{2}$ concentrations 